\title{
Central nervous system vasculitis in a patient with HIV infection: a diagnostic challenge
}

Vasculite do sistema nervoso central em um paciente com infecção por HIV: um desafio diagnóstico

Nícolas de O. Amui ${ }^{1 *}$, Roberta G. F. Silva ${ }^{2 \star}$, Danilo M. C. Costa ${ }^{3}$, Orlando G. P. Barsottini ${ }^{1}$, José Luiz Pedroso', Paulo Roberto Abrão Ferreira ${ }^{2}$

A 37-year-old woman with HIV infection (CD4: 5 cells/ $\mu$ l) presented with acute dysarthria and right hemiparesis. A brain CT showed nodular hyperdense lesions; MRI depicted cortico-subcortical hyperintense signals (Figure 1); MRI and CT angiography disclosed arterial stenosis suggesting vasculitis (Figure 2). The cerebrospinal fluid PCR confirmed cytomegalovirus infection. Highly-active antiretroviral therapy was started, but there was worsening of the symptoms, and she died one month later. Brain necropsy confirmed toxoplasmosis.

CNS vasculitis in HIV patients may be caused by several infectious diseases ${ }^{1}$, such as CMV, toxoplasmosis, HIV virus, and others ${ }^{2}$. In this report we describe a HIV-infected patient with cerebral vasculitis related to co-infection.
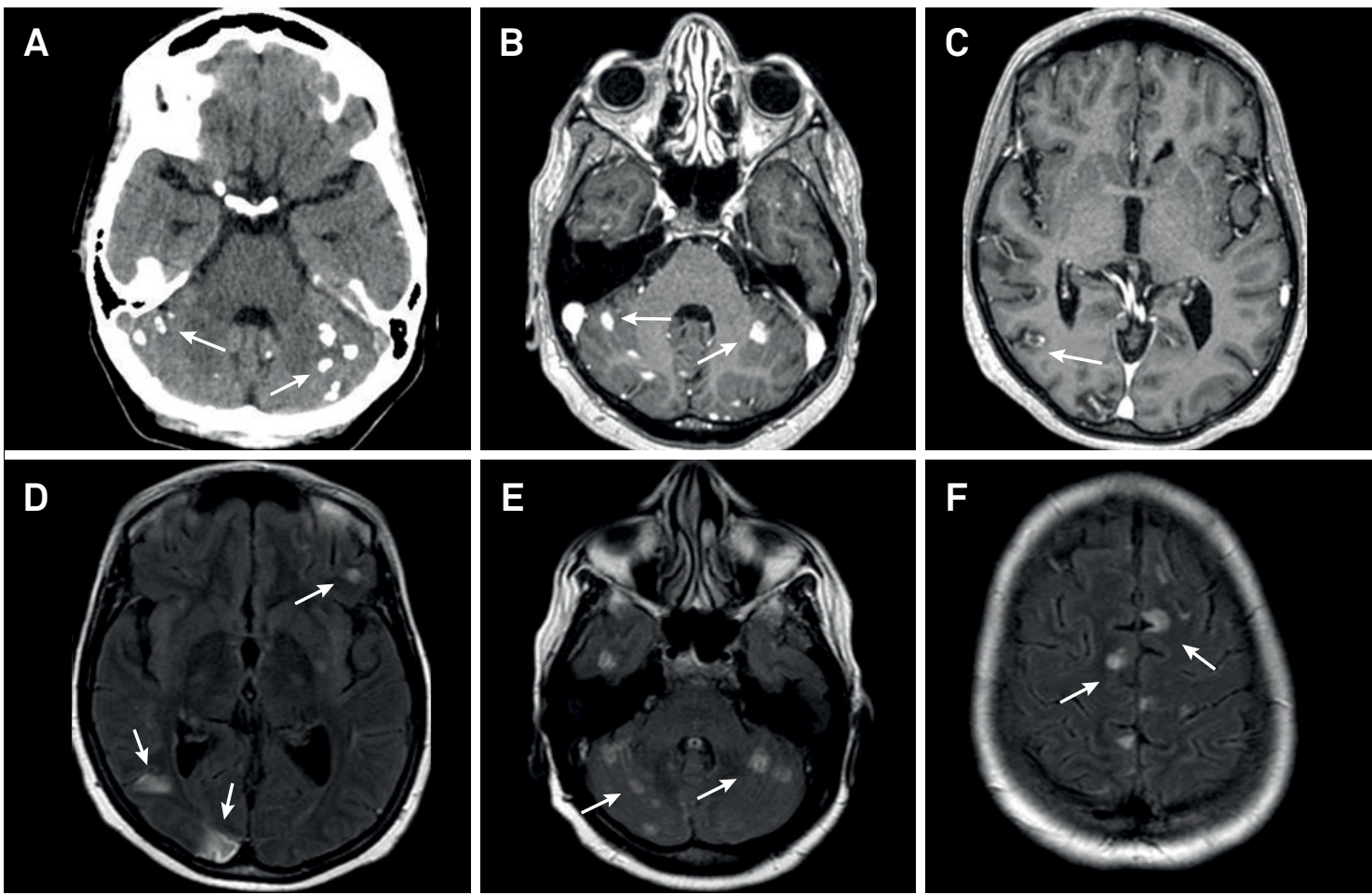

Figure 1. Axial brain CT scan without contrast shows calcification in the cerebellar hemispheres (A). Axial T1-weighted brain MRI shows corresponding areas of nodular and irregular enhancement by the gadolinium (B and C). Axial FLAIR brain MRI demonstrates several areas of hyperintense signal in the cerebral cortex and cerebellum (D, E and F).

\footnotetext{
'Universidade Federal de São Paulo, Departamento de Neurologia, São Paulo SP, Brasil; ${ }^{2}$ Universidade Federal de São Paulo, Divisão de Doenças Infecciosas, São Paulo SP, Brasil; ${ }^{3}$ Universidade Federal de São Paulo, Departamento de Radiologia, São Paulo SP, Brasil.

Correspondence: Roberta Gunutzmann Ferreira Silva; Divisão de Doenças Infecciosas da UNIFESP; Rua Napoleão de Barros, 715; 04023-900 São Paulo SP, Brasil; E-mail: robertanutz@hotmail.com

*The first two authors contributed equally to this work.

Conflict of interest: There is no conflict of interest to declare.

Received 23 January 2017; Received in final form 06 September 2017; Accepted 18 September 2017.
} 

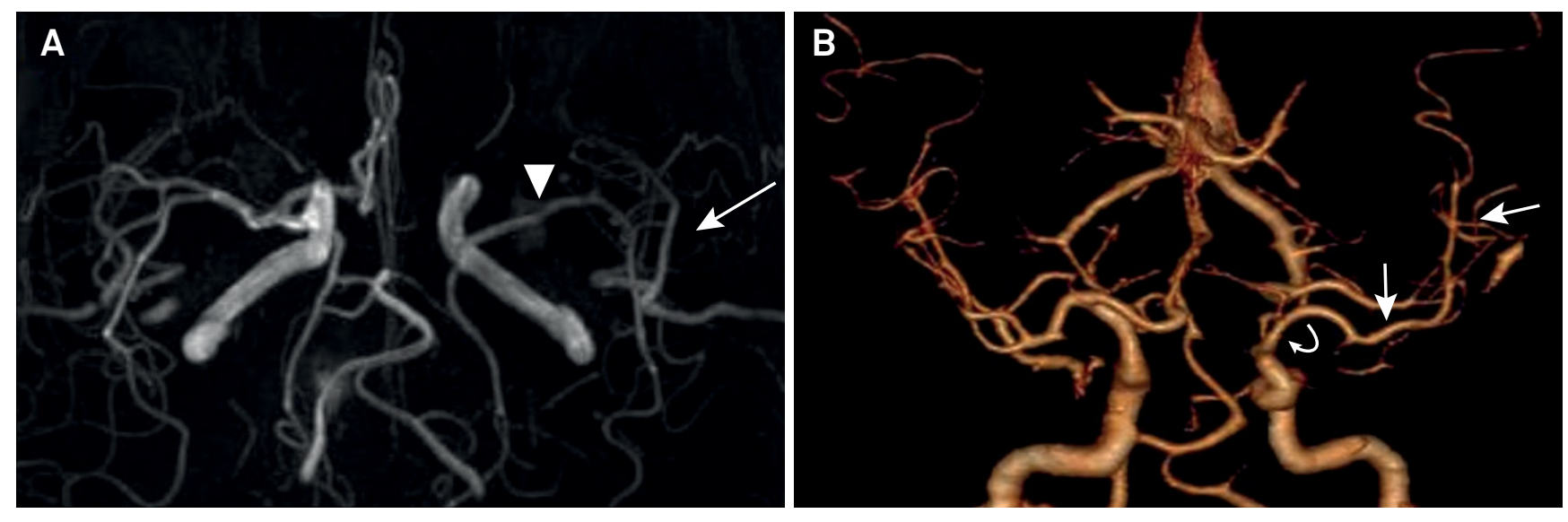

Figure 2. Brain MRI angiography shows segmental narrowing of the left middle cerebral artery (arrowhead) with reduction of flow in the opercular segments (arrow) (A). Follow up with brain CT scan angiography shows focal narrowing of the supraclinoid portion of the left internal carotid artery (curved arrow) and reduction of the flow in the left middle cerebral artery (straight arrow) (B).

\section{References}

1. Hajj-Ali RA, Calabrese LH. Diagnosis and classification of central nervous system vasculitis. J Autoimmun. 2014;48-49:149-52. https://doi.org/10.1016/j.jaut.2014.01.007
2. Finsterer J, Frank M. Parasitoses with central nervous system involvement. Wien Med Wochenschr. 2014;164(19-20):400-4. https://doi.org/10.1007/s10354-014-0307-8 